\title{
Oligoclonal Bands Measurement
}

National Cancer Institute

\section{Source}

National Cancer Institute. Oligoclonal Bands Measurement. NCI Thesaurus. Code C122139.

The determination of the amount of oligoclonal bands in a biological specimen. 